\title{
Emergency Cholecystectomy in Situs Inversus Totalis: Report of a Case
}

\author{
Dr. G M Naikoo*, Dr. Imtiaz Wani ", Dr. Imran Mir", Dr. Fozia Jan **, \\ Dr. S Mushtaq ${ }^{* *}$ and Prof. Mir Nazir Ahmad ${ }^{* * * *}$ \\ "Postgraduate, "** Registrar, "** Head, Department of Surgery, SMHS \\ Hospital/SKIMS, Srinagar, India
}

(Received 28 April 2007 and accepted 13 July 2007)

\begin{abstract}
Situs inversus totalis is a rare anomaly with a genetic predisposition, characterized by transposition of organs to the opposite side of the body. The condition may present difficulties in the management of abdominal pathologies and if undetected can create a diagnostic puzzle. Herein we report a case of situs inversus totalis with acute cholecystitis and the patient underwent successful emergency open cholecystectomy.
\end{abstract}

KEY WORDS: Situs inversus totalis, Cholecystectomy, USG, CT scan.

\section{INTRODUCTION:}

Situs inversus is a form of heterotexia and was first described by Fabricius in humans. It can be either partial or total depending upon whether it is associated with dextrocardia or not. There is no racial predilection and both sexes are equally affected. The recognition of situs inversus is important for preventing surgical mishaps that result from the failure to recognize the reversed anatomy as may happen in cases of cholelithiasis or appendicitis. Diagnosis can be readily established by using radiography or sonography. However CT is the preferred investigation for its diagnosis. Presently there is opinion of increased use of emergency open cholecystectomy in patients of acute cholecystitis ${ }^{\mathbf{1}}$.

\section{CASE DETAILS:}

A thirty seven year old non-hypertensive nondiabetic married male presented to the casualty department of SMHS hospital Srinagar with history of left upper abdominal pain associated with nausea and vomiting. General physical examination was normal. Cardiovascular examination revealed the apex beat in the right $5^{\text {th }}$ intercostal space with mild tachycardia. Abdominal examination showed tenderness in the left hypochondrium with guarding and rigidity. The hematological and biochemical parameters were normal. Chest x-ray revealed dextrocardia and ECG showed transposition of lead $1^{\text {st }}$ and $2^{\text {nd }}$ and inversion of lead $1^{\text {st }}$. Ultrasound examination revealed liver and gall bladder on the left side and spleen on the right of the abdomen. The gall bladder showed the features of acute cholecystitis and presence of multiple calculi (Figure 1). CT scan confirmed the findings of situs inversus totalis (Figure 2).

Corresponding Address: Dr. Imtiaz Wani, Department Of Surgery, SMHS Hospital/SKIMS, Srinagar, India, Email: imtazwani@yahoo.com 


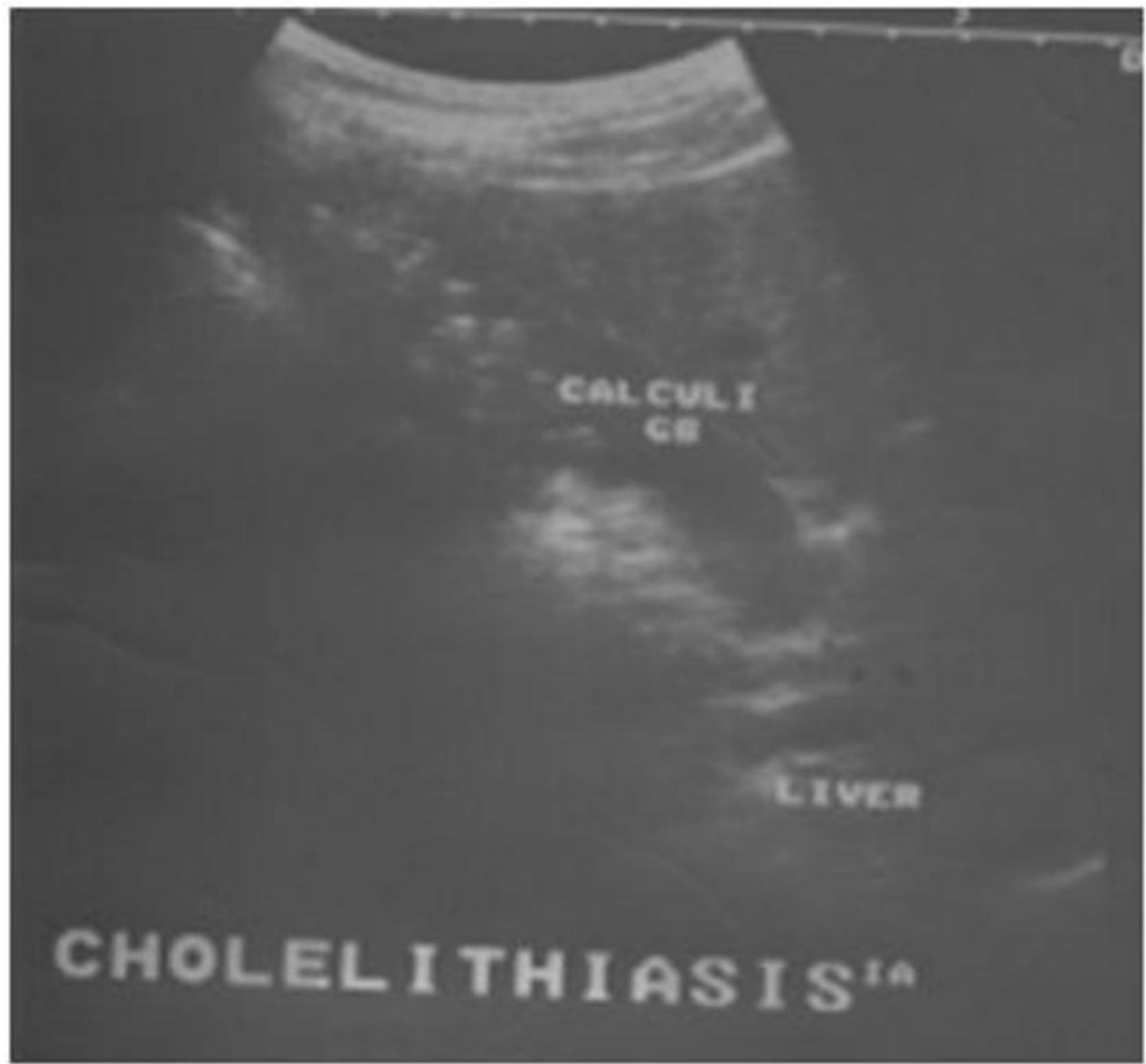

Figure 1: USG Abdomen showing acute cholecystitis

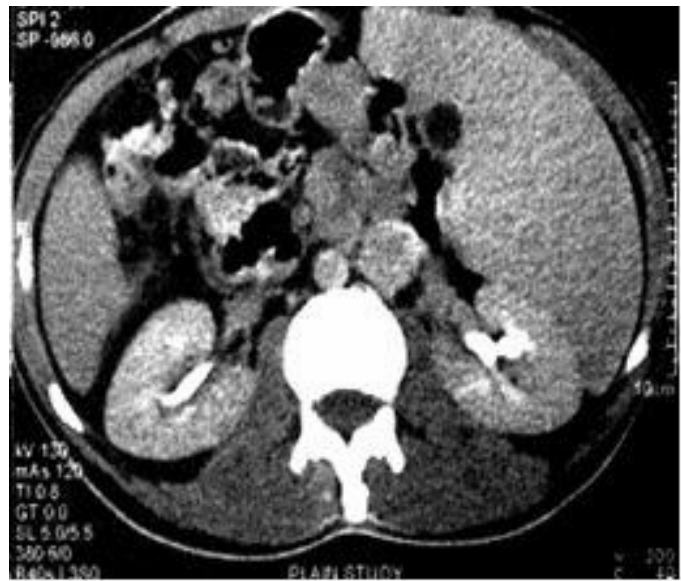

Figure 2: CT abdomen demonstrating left sided gall bladder

Patient underwent emergency open cholecystectomy through a left subscostal incision within twenty four hours of admission. The operating surgeon was on the left side of the patient. Peroperative findings revealed features of acute attack of cholecystitis and gall bladder was partly intrahepatic with multiple calculi; CBD was normal. Postoperative period was uneventful. 


\section{DISCUSSION:}

Situs inversus totalis is a rare defect with a genetic predisposition and can present difficulties in the management of abdominal pathologies $^{2}$. The incidence has been found to vary from $1: 4000$ to $1: 20000^{3}$. The exact etiology of situs inversus is not clear. However genetic defect thought to occur either at conception or within two weeks of embryonic life has been implicated by some ${ }^{4}$. Acute calculous cholecystitis with situs inversus has been reported by many authors and these patients usually present with left hypochondrial pain with nausea and vomiting ${ }^{5}$. The symptoms may mimic a hiatus hernia, peptic ulcer disease or pancreatitis. So a thorough clinical examination should be made along with the relevant investigative procedures to detect situs inversus preoperatively. Rate of preoperative and intraoperative diagnosis for detecting situs inversus with cholelithiasis, prior to the use of chest $\mathrm{x}$-ray, USG and CT scan abdomen, was $55 \%$ and $32 \%$ respectiy ${ }^{6}$.

Laparoscopic cholecystectomy in situs inversus has also been performed safely and should be the procedure of choice wherever the expertise is available ${ }^{\mathbf{2 , 7}, \mathbf{8}}$. In acute cholecysititis for emergency surgery, open cholecystectomy is unavoidable where difficulty is anticipated?

\section{CONCLUSION:}

A high degree of suspicion combined with a thorough clinical examination should be maintained by an experienced surgeon while evaluating a patient with left upper abdominal pain. An open cholecystectomy should be performed in emergency situation when there is limited access to laparoscopic surgery.

\section{REFERENCES:}

1. Cameron IC, Chadwick C, Phillips C. Current Practice in the management of acute cholecystitis. $\mathrm{Br} \quad J \quad$ Surg. 2000 Mar;87(3):362-73.

2. Pitiakoudis M, Tsaroucha AK, Katotomichelakis M, et al. Laparoscopic cholecystectomy in a patient with situs inversus using ultrasonically activated coagulating scissors. Report of a case and review of literature. Acta Chir Belg. 2005 Feb;105(1):114-7.

3. Demetriades H, Botsios D, Dervenis C, et al. Laparoscopic cholecystectomy in two patients with symptomatic cholelithiasis and situs inversus totalis. Dig Surg. 1999;16(6):519-21.

4. Gray SW, Skandalakis JE. Embryology for surgeons. The embryological basis of treatment for congenital defects. Philadelphia WB Saunders. 1972;880-3.

5. Heimann T, Sicular A. Acute cholecystitis with situs inversus. NY state J Med.1979 Feb;79(2):253-4.

6. Pathak KA, Khanna R, Khanna NN. Situs inversus with cholelithiasis. J postgrad Med. 1995 Apr-Jun;41(2):45-6.

7. Blgen HM. Surgery in situs inversus. Ann Surgery 1949 Feb;129(2):244-59.

8. Crosher RF, Harnarayan P, Bremner DN. Laparoscopic cholecystectomy in situs inversus totalis. J R Coll Surg Edinb. 1996 Jun;41(3):183-4.

9. Puglisi F, Troilo VL, De Fazio M, et al. Cholecystectomy in situs viscerum inversus totalis. Does laparoscopy increase the pitalls? Chir Ital. 2006 Mar-Apr;58(2):17983. 